NBER WORKING PAPER SERIES

\title{
LIMITED INSURANCE PORTABILITY AND JOB MOBILTY: THE EFFECTS OF PUBLIC POLICY ON JOB-LOCK
}

Jonathan Gruber

Brigitte C. Madrian

Working Paper No. 4479

\section{NATIONAL BUREAU OF ECONOMIC RESEARCH 1050 Massachusetts Avenue \\ Cambridge, MA 02138 \\ September 1993}

We are grateful to John Abowd, Maria Hanratty, Olivia Mitchell, and participants at the Cornell Seminar on Health Insurance and the Labor Market for helpful comments, and to Aaron Yelowitz for his help in creating the SIPP extracts. This paper is part of NBER's research programs in Health Care, Labor Studies, and Public Economics. Any opinions expressed are those of the authors and not those of the National Bureau of Economic Research. 


\title{
LIMITED INSURANCE PORTABILITY AND JOB MOBILITY: THE EFFECTS OF PUBLIC POLICY ON JOB-LOCK
}

\begin{abstract}
The link between health insurance and the workplace in the U.S. has led to concern over the possibility of insurance-induced reductions in job mobility or "job-lock". Designing health insurance reforms which retain employer-based insurance coverage but mitigate the extent of joblock requires an understanding of the policy dimensions to which job-lock is most receptive. We study a policy of limited insurance portability which has been adopted by a number of states and the federal government over the last 20 years. These "continuation of coverage" mandates grant individuals the right to continue purchasing health insurance through their former employers for some period of time after leaving their jobs. We find that the passage of these mandates caused a significint increase in the job mobility of prime age male workers. This suggests that a sizeable share of job-lock arises from short run concerns over portability rather than from long run problems.
\end{abstract}

Jonathan Gruber

Department of Economics

Massachusetts Institute of Technology

50 Memorial Drive

Cambridge, MA 02139

and NBER
Brigitte C. Madrian

Department of Economics

Harvard University

Littauer Center

Cambridge, MA 02138

and NBER 
The predominant feature of private health insurance in the U.S. today is its link with employment. Workplace pooling of risks has several advantages: it allows for economies of scale in administration; it reduces the problem of adverse selection as long as workplaces are chosen independently of health status; and it allows individuals to take advantage of the non-taxation of employee fringe benefits. However, there is one important disadvantage as well. If wages do not perfectly offset differences in the valuation of health insurance across different jobs, then individuals may not change jobs even when new employment opportunities with higher match-specific productivity arise.

Recent research has demonstrated the empirical significance of this type of job-lock. Madrian (1992) estimates insurance-induced reductions in mobility of approximately $25 \%$. Given a distortion of this magnitude, it is obviously important to ask how public policy can alleviate job-lock. One solution is to divorce health insurance coverage from the employment relationship; pooling could occur along other dimensions, such as regionally (as proposed in Diamond 1992) or nationally (as with Canadian National Health Insurance). However, policies which change the fundamental nature of health insurance coverage in the U.S., where $83 \%$ of all private insurance is provided through the workplace (Gruber 1992a), have enormous transition costs which may make them infeasible.

Another alternative is to maintain employment-based insurance but to ensure portability of coverage across jobs. A policy of full insurance portability raises a number of difficult design issues, however. For example, will employees who change jobs frequently be covered by their first employer, each employer in succession, or the employer of their choice? Each of these policy options has difficulties. If the initial employer is responsible for all future insurance, this will lead to both large distortions in initial hiring decisions and massive administrative costs in tracking 
employees through their job changes. If each subsequent employer is responsible, it will be difficult to guarantee individuals fully comparable coverage on each job; if coverage is less generous elsewhere, the problem of job-lock remains.

The potentially least disruptive option is to continue having individuals receive insurance from their current employer but to forbid both the exclusion of preexisting conditions and the growing practice of medical underwriting.' In this way, individuals could be assured coverage if they changed jobs. The prohibition of these instruments, however, may make it infeasible for many small firms to offer insurance, since one very sick employee with sufficiently high medical expenses could drive the firm out of business. Thus, with no other government action, many small firms may cease to offer health insurance at all. Even if all firms were mandated to provide coverage, mechanisms would be required to reinsure small firms against these major shocks to their risk pools. Thus, effective implementation of this policy option may require much more than simple insurance market regulation.

The key point is that the design of policies to alleviate labor market distortions without radical change to our health care system is an important and difficult issue. In considering various alternatives, it may be useful to reflect upon our experience with the major policy intervention to date in this area: the limited portability of health insurance provided by "continuation of coverage mandates. These mandates grant individuals the right to continue purchasing health insurance through a previous employer for a specified number of months after leaving the firm. Although individuals must pay the full average cost of their group insurance, the price may be well below that

\footnotetext{
I A preexisting condition is generally defined as any medical problem which has been treated or diagnosed within the past six months to two years. In some cases it may be more broadly defined as any medical problem for which an individual has ever received care. It may also be extended to include medical conditions for which a prudent person would have sought care even if no physician was actually consulted. Insurance companies may also require medical examinations of all employeer which they then use to exclude certain medical conditions on an individual basis for the life of the contract. This practice is known as medical underwriting.
} 
of a policy purchased in the individual market, especially for individuals with high medical expenditures. Thus, continuation benefits provide a way for workers who leave their jobs to maintain their health insurance coverage, for some period of time at least, when the alternative would most likely be to go uninsured.

In recent research, we have found that these mandates have large effects on the retirement behavior of older workers (Gruber and Madrian 1993). The goal of this paper is to study whether these policies have also been effective in alleviating job-lock. If they have, it suggests that we may be able to reduce job-lock and still retain the advantages of employer-provided health insurance coverage.

We study the effects of continuation of coverage mandates by exploiting variation in their timing and generosity. Continuation of coverage laws were passed at different times and in different states from the mid-1970s through the mid 1980 s before being federally mandated in 1986 . In addition, some laws were quite liberal, allowing 15-20 months of coverage, while under others the extent of coverage was minimal. We use data from the Survey of Income and Program Participation (SIPP) to study the effects of these laws on job mobility and subsequent insurance coverage.

Our basic finding is that the availability of continuation coverage has significant effects on job mobility. We estimate that these mandates caused a $10 \%$ increase in the mobility rates of prime age male workers. While small in absolute terms, this is $40 \%$ of the reduction in mobility resulting from job-lock estimated in Madrian (1992). This suggests that a substantial fraction of job-lock is due to individuals who are hindered by short-run medical expenditures, a conclusion which is consistent with Holtz-Eakin's (1993) finding that job-lock appears to be primarily a short-run phenomenon. We also find significant effects of these mandates on insurance coverage; the estimates 
suggest that much of the effect of the mandates to increase insurance coverage among individuals who would have changed jobs even in their absence.

The paper proceeds as follows. Section I provides some background on health insurance and job mobility. Section II describes the continuation of coverage laws and their expected effects on mobility, and Section III discusses our data and the regression framework. This is followed by our empirical results on job mobility in Section IV and evidence on the effects of continuation mandates on insurance coverage in Section V. The paper concludes in Section VI with a discussion of the public policy implications of our findings.

\section{Health Insurance and Job Mobility}

The primary problem with workplace pooling of risks is that workplaces are not necessarily chosen independently of underlying health status. This has led many insurers to exclude preexisting conditions for some period of time after an individual is hired, typically between six months and two years. The New York benefits consulting firm Foster Higgins reports that $57 \%$ of employers excluded preexisting conditions in their health plans in 1987 (Cotton 1991). Furthermore, almost half of full-time workers in firms of 250 employees or more face a length of service requirement before being eligible for any health insurance coverage (Bureau of Labor Statistics 1989). Although the length of service requirement is generally short, it may be important for the employee anticipating major medical expenses.

In addition, for small firms whose insurance premiums are experience rated, hiring a sick employee can entail large increases in insurance costs. As a result, employees with medical problems may face potential discrimination in finding a new job with coverage. ${ }^{2}$ Even if there is

\footnotetext{
${ }^{2}$ Although such explicit behavior is outlawed under the Americans with Disabilities Act.
} 
not explicit discrimination in hiring, many insurance policies at small firms are now medically underwritten so that sick employees may not be able to qualify for coverage. Furthermore, only $60 \%$ of firms with less than 100 employees even offer insurance, so that a new job with insurance coverage is far from guaranteed for the potential job changer (Gruber 1992a).

The theory of compensating differentials predicts that in a perfectly competitive labor market, differences in the generosity of benefits across firms will be reflected in wages or other aspects of compensation. However, as Rosen (1986) notes, the compensating differential for a given health insurance package will equate the wage reduction to the valuation of that package by the marginal worker who is just indifferent between wages and benefits. In a heterogenous population, some workers will value health insurance more highly than the marginal worker; these "inframarginal" workers will receive a surplus from their excess valuation of the benefit. That is, these workers will value total compensation at their current job at above the sum of their wages plus the cost to the employer of providing the benefit.

As a result, these workers may turn down alternative employment opportunities for which their total productivity would be higher and which pay higher wages but which do not offer comparable health insurance. The potential market failure here arises from the lack of a complete market for worker/job specific compensation packages. If firms could truly identify worker valuation of benefits, and if they could offer each individual a customized wage and benefits package, then workers would move to jobs where their productivity would be highest.

However, offering worker-specific compensation packages is generally not feasible for a number of reasons. First, such packages would violate a number of rules designed to guard against discrimination in the design of benefit plans. One clear example is the ruling under the Employee Retirement Income Security Act (ERISA) that all firms offering health insurance must do so for any 
employee working more than 1000 hours per year. Second, even if worker-specific compensation were allowed, it is difficult to elicit true worker valuation of these benefits, so that such workerspecific compensation would be difficult to design. Finally, the costs involved in administering such packages may be large enough to absorb most of the rents which the worker would earn from their existence.

Although this market failure will exist for any job amenity, such as workplace safety, pensions, or parking, there are two reasons why it may be more important for health insurance than for other job amenities. First, the variance in employee valuation of health insurance is, in general, much greater than the variance in the valuation of other benefits. This is due to both the high cost of medical care and the substantial variation across individuals in their underlying health status. Medical expenditures among those aged $20-54$ averaged $\$ 1200$ in 1990 , with a standard deviation of \$3878. ${ }^{3}$ Large differences in the productivity of an employee across different firms may therefore not be sufficient to induce mobility if other firms do not provide health insurance or if the insurance excludes preexisting conditions or is medically underwritten.

Second, there are very large differences across firms in the costs of providing health insurance, particularly by firm size. The costs of insur ance in the largest $(10,000+$ employee $)$ firms is estimated to be $40 \%$ lower than the cost in smaller (1-4 employee) firms (Congressional Research Service 1988). This will make it difficult for small firms to offer insurance, even if they know that they could attract much higher productivity workers by doing so.

\footnotetext{
${ }^{3}$ Authors' calculations using data from the 1980 National Medical Care Utilization and Expenditure Survey (inflated to \$1900).

4 One other interesting point about health insurance, relative to other job amenities such as workplace safety, is that it does not, by definition, need to be tied to the employment relationship. This allows the use of a range of policy instruments, such as rogional of national pooling of risks, to alleviate job-lock of this type. As noted in the iniroduction, our discussion focuses on policy options which retain the link between health insurance and employment.
} 
The welfare consequences of health insurance-induced job-lock are unclear (Madrian 1992). Many studies have found large increases in wages for workers who switch to new jobs (Minter 1992; Bartel and Borjas 1977; Mincer 1986; and Topel 1986). This may represent a gain to society from the increased productivity of an improved job match. On the other hand, it may be that some jobs offer rents to workers, and that individuals tend to move into these jobs as their careers advance. Furthermore, a key consideration will be the temporal nature of the job-lock. If individuals are locked in by chronic illnesses, this could have major and long lasting consequences for their job productivity; lock-in by short-term conditions such as pregnancy may be less important from a lifecycle perspective.

Finally, it can be argued that job-lock allows firms to reap the returns from general human capital investments by reducing the ability of workers to use those investments elsewhere. However, job-lock seems a particularly inefficient mechanism for achieving this goal, relative to back-loaded compensation devices such as pensions, since presumably it is not just the sickest workers that the firms wishes to retain.

\section{Alleviating Job-Lock Through Continuation Benefits}

State and federal continuation of coverage laws mandate that employers sponsoring group health insurance plans offer terminating employees and their families the right to continue their health insurance coverage through the employer's plan for a specified period of time. The laws generally apply to all separations (except those due to an employees gross misconduct), although in some states benefits are restricted to those who leave their jobs involuntarily.' They often also provide benefits

\footnotetext{
s We consider only states with laws that cover both voluntary and involuntary separations since we only have very noisy data on the nature of the separation.
} 
to divorced or widowed spouses and their families. The first such law was implemented by Minnesota in 1974. More than 20 states passed similar laws over the next decade before the federal government, as part of its 1985 Consolidated Omnibus Budget Reconciliation Act (COBRA), mandated such coverage at the national level.

The various state statutes are summarized in Table 1." The length of coverage is generally quite short, from 3-6 months, although 10 states mandate coverage of nine months or more. Most state laws stipulate that an employee must have been covered by an employer's insurance for 3-6 months before being eligible for continuation coverage. The states laws also apply only to firms that actually purchase insurance through an insurance company; self-insured firms, under the 1974 Employee Retirement Income and Security Act (ERISA), are not subject to these (or any other) state mandates.

Although similar in spirit, the state and federal laws differ in a number of important ways. First, the length of coverage mandated under the federal law, 18 months, equals or exceeds that mandated by all but one state (as of January 1987, Connecticut law provides for up to 20 months of coverage). ${ }^{?}$ Second, there is no minimal length of time for which an employee must be covered under an employer's plan before being eligible for continuation benefits. Third, the federal law applies to self-insured firms, who are exempt from the state laws, as well as to those who purchase their coverage from insurers. The federal law, however, does not apply to small firms employing less than 20 workers. Finally, employees of religious organizations and the federal government were

\footnotetext{
6 Details on state laws are from Hewitl (1985) and Thompson Publishing (1992) and have been cross-checked against the actual statutes. Table 1 lists only those states with laws that apply to employees who terminate their employment voluntarily.

718 months is the maximum length of coverage available following the voluntary or involuntary termination of employment. COBRA also provides up to 36 months of coverage for family members who would otherwise lose their insurance coverage through events such as an employee's death, divorce from the employee. or the employee's eligibility for Medicare.
} 
exempt from COBRA, although federal employees have subsequently been included (beginning in 1990). When the specific details of the state and federal statutes are at odds, firm provision of continuation benefits is governed by the law which provides for more generous coverage.

An important feature of continuation coverage from our perspective is the interaction between continuation coverage from an old job and insurance coverage from a new job. Before 1990, once individuals who were continuing their health insurance benefits from their old jobs obtained new employment which offered health insurance, the former employers could drop their continuation benefits, regardless of whether they were covered by the new policy. This is important because moving to a firm which offers insurance does not guarantee coverage if the firm excludes preexisting conditions from its policy, or if it has a length of service requirement. After 1990, individuals were allowed to continue their COBRA coverage even if they started a new job with health insurance, as long as they continued to pay the required premiums. This improved the portability features of COBRA, since it could now be used to bridge periods of non-coverage due to either length of service requirements or preexisting conditions exclusions."

The effective dates of the state laws are listed in Table 1. The federal coverage mandated under COBRA was phased in. Beginning in July 1986, firms had to offer continuation benefits at the start of their next plan year. For workers provided health insurance under union contracts, such benefits did not have to be offered until the next contract negotiation after January 1987.

Both the state and federal laws stipulate that the employee must pay the full cost of the coverage. At the federal level, this is defined specifically as $102 \%$ of the average employer cost of providing coverage. The coverage must be identical to that provided to similarly situated active

\footnotetext{
- Whether this was much of a change in practice is unclear, since it is not obvious how the old employer could verify that the employee had obtained new employment which offered health insurance coverage.
} 
employees, including the option to continue enrollment in supplemental insurance plans (such as for vision or dental care) if these are available. While this is substantially more than the individual generally had to pay as an employee, it may still be much more attractive than purchasing individual insurance, due to the economies of scale in administering group insurance and the reduced potential for adverse selection with large employee groups.

In Massachusetts, the average cost of family health insurance coverage per employee in 1989 was $\$ 3882 .{ }^{9}$ When inflated by the medical care component of the Consumer Price Index, this is equivalent to $\$ 5047$ in 1993 dollars. In contrast, a New England commercial insurance company is offering a family policy for a 40 year-old male with a wife and two children, with a 1 -year exclusion of preexisting conditions, for $\$ 7000$. Thus, there is a non-trivial financial savings for such an individual in purchasing continuation benefits over individual coverage.

Furthermore, for less healthy persons or those with high family medical expenses, individual coverage will be even less attractive for two reasons. First, it is often medically underwritten, so that it may be much more expensive than the figure given above, or not available at all. Second, individual coverage is typically much less generous than group policies. For example, the policy cited above excludes preexisting conditions for one year, while such conditions would be covered for someone continuing a group policy. Table 2 compares the health insurance benefits of individuals covered under group and nongroup policies in 1977. In every category, those covered under nongroup policies receive more limited benefits. Relative to those with nongroup coverage, those with group policies are more than twice as likely to receive major medical coverage or coverage for physician office visits and prescription drugs, and more than 50 percent more likely to

\footnotetext{
'Authors' calculation using unpublished data from the Health Insurance Association of America.
} 
receive ambulance, mental health, and outpatient diagnostic service coverage. Furthermore, nongroup policies generally feature both higher deductibles and higher copayments.

Thus, while for a healthy person continuation coverage may provide only modest savings, for persons with high expected medical expenditures the difference in costs may be quite sizeable. Since this is exactly the population for which job-lock is potentially the largest problem, continuation mandates may potentially have some effect in alleviating this distortion.

Table 3 tabulates the sources of health insurance coverage among $20-54$ year-old males from the 1987 National Medical Expenditure Survey. $66 \%$ of persons in this age group have employerprovided health insurance; the majority of that coverage is in their own name. Individuals who leave jobs are much less likely to have had insurance coverage on those jobs. This could be construed as evidence of job-lock; on the other hand, it may just be that individuals are more likely to leave "bad" jobs which do not offer health insurance.

An important indication of the potential effectiveness of continuation mandates is the extent to which eligible persons take up these benefits. Using data from a company which administers COBRA claims, Flynn (1992) estimates that $19.3 \%$ of individuals who were terminated, laid-off, or quit from firms which had health insurance chose to take up continuation benefits. ${ }^{10}$ As Klerman and Rahman (1992) note, this represents a lower bound on the takeup rate of benefits among the eligible population since many of these persons will move to new jobs with health insurance or are covered by their spouses. Data from the 1987 National Medical Expenditure Survey (NMES) suggest that about two-thirds of those who leave jobs with health insurance move to jobs where they

\footnotetext{
${ }^{10}$ This figure excludes retirees. This is important, as takeup among this population is likely to be substantially higher (see Gruber and Madrian 1993).
} 
also receive health insurance;" these are individuals who we would not expect to take-up continuation benefits (this figure actually represents and upper bound on the fraction who move to jobs with health insurance as the NMES does not distinguish between those who receive health insurance through their current employer and those who receive COBRA benefits through a former employer). Klerman and Rahman estimate that and additional $10 \%$ of job leavers who don't find jobs with health insurnace are covered by their spouse's health insurance, a group we would also expect to not be affected by COBRA.

Based on this information, we would expect approximately $30 \%$ of those who leave jobs with health insurance to be affected by COBRA. This implies COBRA takeup rates among those for whom we would expect it to matter of about $65 \%$. It therefore appears that a sizeable fraction of eligible job changers avail themselves of continuation benefits, despite the high out-of-pocket costs.

Should we expect continuation mandates to alleviate job lock? The answer depends on the nature of this distortion. If much of job-lock arises due to short-run medical considerations, such as pregnancy, then these policies may be quite effective. On the other hand, if individuals are worried about long-run coverage, then even 18 months of continuation benefits may not be sufficient. ${ }^{12}$ Furthermore, if job-lock arises from fear of moving to jobs with length of service requirements or limited pre-existing conditions exclusions, then temporary coverage may be all that is necessary ${ }^{13}$; if it is fear of being medically underwritten out of coverage, then more permanent portability is required. Finally, if job-lock primarily occurs among individuals with very high

\footnotetext{
"Authors' calculation.

${ }^{12}$ Prior evidence on this front is mixed. Madrian (1992) finds job-lock arising from both pregnancy, which is a short-run expenditure, and larger families, which gives rise to longer run expenditures. Holtz-Eakin (1993) finds that job-lock appears to operate for short-run job changes only; mobility males over periods of more than one year do not show evidence of job-lock.
}

13 Although, in this case, continuation benefits in the period after 1990 would be much more effective. 
expected medical costs, then continuing to pay the cost of group health insurance will not be a major deterrent to the use of continuation benefits. However, if job-lock represents risk aversion on the part of the average person, then continuation benefits may not seem a reasonable option financially. Thus, by examining the effects of continuation mandates on mobility, we can hopefully draw some lessons as to the nature of the job-lock problem itself.

\section{Data and Regression Framework}

The data we use come from the 1984, 1985, 1986 and 1987 panels of the Survey of Income and Program Participation (SIPP). This nationally representative survey collected information on the economic and demographic characteristics of individuals and their families through a series of quarterly interviews, referred to as "Waves", for roughly $2 \frac{1}{2}$ years. ${ }^{14}$ Because the panels overlap, as many as three panels may be interviewed concurrently. Altogether, these four panels span the period from June of 1983 to April of $1989 . .^{15}$

During each interview, respondents were asked questions on up to two jobs held during the previous 4 calendar months, including the industry, occupation, hours worked, and pay of each job, as well as the date that an individual commenced and/or terminated each job, if it was held for less than the full quarter. With this information, we are able determine whether an individual changed jobs or ceased to be employed during the quarter.

\footnotetext{
14 The 1984 Panel of the SIPP, which has 9 waves, covers 3 years. The 1985 Panel consists of 8 waves (32 months), while the 1986 and 1987 Panels both include 7 waves.

15 While we would ideally like to have data from before 1983 in order to study the 14 state continuation of coverage laws that were passed prior to that time, the period that is covered by the data provides a window around the passage of the federal law and includes 19 state laws which took effect after June of 1983.
} 
Our sample is restricted to men between the ages of 20 and 54 who were not in school over the course of their participation in the SIPP and who were not self-employed. ${ }^{16}$ We exclude individuals from Hawaii, which has mandated health insurance for all employees, and West Virginia, for which we were unable to definitively date their continuation mandate. Individuals from several other small states are also excluded because, out of concern for confidentiality, the SIPP has grouped these states together, thereby making it impossible to assign the appropriate state laws to individuals in these states. ${ }^{17}$ The final sample consists of 155,151 quarterly observations on 29,841 individuals.

We use these data to estimate a model of quarterly job turnover. Turnover is defined as changing employers, becoming self-employed, or becoming unemployed. ${ }^{18}$ Overall, the quarterly turnover rate for our sample is $10 \%$, while $24 \%$ of each panel changes jobs within the first year. This is similar to the annual turnover rate of $22.6 \%$ that is estimated from the 1987 National Medical Expenditure Survey.

To calculate the wages associated with the job that an individual left, we divide the quarterly wage and salary earnings of the job by the usual hours worked per week multiplied by the number of weeks in the quarter for which an individual was employed in that job. The wage rate computed in this manner is highly correlated with the hourly wage rate reported by those who are paid hourly.

\footnotetext{
${ }^{16}$ We exclude 55-64 year olds because the effects of continuation mandates on retirement behavior may be quite different than their effects on job mobility. We focus on the older group of workers in Gruber and Madrian (1993), finding sizeable effects of continuation mandates on retirement. We excluded women because the process determining their job mobility may be quite different than that for men.

17 These states are Alaska, Idaho, Iowa, Maine, Mississippi, Montana, New Mexico, North Dakota, South Dakota. Vermont and Wyoming.

10 While our definition of turnover includes the switch from employment to selfemployment, it does not include moving from one self-employed job to another as individuals are excluded from the sample when they are selfemployed.
} 
Each individual is assigned the maximum months of continuation coverage available at the beginning of the Wave under either COBRA or the appropriate state law. Because the federal law was phased-in between July of 1986 and June of 1987 , we increment the months of coverage available under COBRA by 1.5 months for each month over this period. By June of 1987 , therefore, months of continuation coverage equals 18 for all individuals except for those who live in Connecticut where state law allows for 20 months of coverage.

Because continuation coverage is only available for those with employer-provided health insurance, an important variable in our analysis is whether or not an individual is covered by such insurance. In each wave, the SIPP asks if an individual is covered by health insurance, if this coverage comes from a policy in one's own name, and, if so, if this policy is provided by an employer or union. In quarters in which individuals do not change jobs, we code them as having employer-provided health insurance if they report being covered by health insurance provided by an employer or union. In quarters in which individuals change jobs and report coverage from employer-provided health insurance, it is not clear from the SIPP questions whether or not the employer-provided health insurance was attached to the first job, the second job, or both. For these individuals, we code their coverage by employer-provided health insurance based on whether or not they report having such coverage in the previous wave of the SIPP. ${ }^{19}$

19 This definition of coverage by employer-provided health insurance will still be somewhat problematic for individuals who change jobs in two consecutive quarters. Of the job changes in our sample, $15 \%$ are immodiately preceded by another quarter with a job change, so that only $1.5 \%$ of our sample are consecutive job changers. Our conclusions about the mobility and insurance coverage effects of the mandates are unchanged when we exclude this group from the analysis. 
The means for our data sample are presented in Table 4. Each observation is a quarter in which a member of our sample does any work. ${ }^{20} 11 \%$ of the sample is non-white, and the average educational level is approximately one year of college. $77 \%$ of the sample holds employer-provided health insurance. As noted above, the quarterly turnover rate is $10 \%$.

The model which underlies the analysis is presented in detail in Madrian (1993). Individuals have different valuation of health insurance, which leads to job-lock through the mechanism described above. We assume that these valuations are distributed randomly in the population that we are studying. ${ }^{21}$ We can examine the effectiveness of continuation benefits in alleviating job-lock through a probit regression of the form:

$$
\operatorname{Pr}(\text { Leave Job })=\Phi\left(\alpha+\beta_{1} \cdot \mathbf{X}_{\mathrm{inh}}+\beta_{2} \cdot \text { State }_{j}+\beta_{3} \cdot \text { Time }_{,}+\beta_{4} \cdot L a w_{h}\right)
$$

where $i$ indexes individuals, $j$ indexes states, and $t$ indexes time. $X_{i j,}$ is a set of individual demographic and job characteristics, State ${ }_{j}$ is a set of state dummies, Time, is a set of year and month dummies, ${ }^{22}$ and $L a w_{j i}$ is the number of months of continuation coverage available in state $j$ at time 1. The regression models the probability that an individual leaves his job in a particular quarter.

We control for a number of characteristics of individuals (education, experience, race) and their jobs (log hourly wage, eight industry dummies, six occupation dummies, and a dummy for the

20 Thus, there are be multiple observations on each individual. Accounting for the resultant intra-personal correlation in the error term has little effect on the results. There is also a potential left-censoring problem which may lead to the type of "dynamic sample-selection" bias noted by Diamond and Hausman (1984). Individuals who left their jobs in response to the availability of continuation benefits, but who were still unemployed one quarter later, will be excluded from our sample. In a bivariate setting, this would lead to a downward bias to our eslimated effect; in a multivariate setting, the effect is unclear. We tested for the importance of this bias in our study of the effect of continuation mandates on retirement (Gruber and Madrian 1993) and found it to be small.

21 Ideally, one would account for these individual differences in valuation and to use them to help identify any potential effects of continuation benefits. We discuss one attempt to do so below.

22 The month dummies are actually a dummies for the month in which the quarter begins. The year dummies are dummies for the year in which the panel begins. 
provision of health insurance). The year dummies control for any national time trends in mobility, and the month dummies control for seasonal mobility patterns. The state dummies control for any time invariant differences across states which may be correlated with their propensity to legislate continuation mandates, such as differences in the underlying valuation of health insurance among the population. The regressor of interest measures the number of months of continuation benefits for which workers are eligible if they leave their current jobs. If continuation of coverage mandates alleviate job-lock, then this regressor should have a positive coefficient.

\section{Erfects on Mobility}

\section{A. Basic Results}

The basic mobility results are presented in Table 5. The covariates have their expected effects. Well-educated and older workers are less likely to change jobs, and workers are much less likely to leave jobs with high wages or health insurance. The negative coefficient on health insurance in the second and third columns of Table 5 cannot be taken as causal evidence of job-lock, since there are a number of other reasons why individuals may be reticent to depart from the "good jobs" that provide health insurance (Madrian 1992). Further evidence for this point is provided by the fact that the wage coefficient in the first column is substantially reduced when health insurance coverage is added to the regression. ${ }^{23}$

The coefficient on the months of continuation coverage variable in the third column is highly significant. In this and the remaining tables, the probability derivative for this coefficient is presented in the last row. It indicates that one year of continuation benefits increased the mobility

\footnotetext{
${ }^{2}$ Madrian (1993) also finds that the wage coefficient falls substantially when health insurance is added as a regressor. Mitchell (1982) finds a similar result for pensions.
} 
rate for individuals in our sample by 0.9 percentage points. This represents approximately $9 \%$ of the baseline quarter-to-quarter mobility rate for the sample. While small in absolute magnitude, this effect is quite sizeable relative to Madrian's (1992) estimate of job-lock; it implies that a year of continuation coverage reduces job-lock by almost $40 \%$.

\section{B. Specification Checks}

The key identifying assumption behind our model is that the passage of these mandates represents an exogenous change in the opportunity set of the worker making a mobility decision. An alternative hypothesis is that the laws themselves are endogenous responses to the pattern of mobility across states. For example, if more individuals are changing (or losing) jobs, states may respond by mandating benefits that cover individuals during this transition. To the extent that the state mandates are responses to long-standing mobility differences across states, the state fixed effects included in the regression will control for this endogeneity. However, to the extent that legislatures are responding to changes in mobility, then state fixed effects will not be sufficient controls.

There is a natural test for this alternative hypothesis, however. Note that only individuals who have health insurance on the job are eligible to receive continuation benefits. Thus, workers without health insurance on the job provide a natural control group for assessing the effects of continuation mandates. If these mandates are simply correlated with, or due to, exogenous changes in mobility propensities, then the laws should be correlated with the mobility of workers both with and without health insurance on the job. However, if the laws are causing changes in mobility patterns, this should only affect workers with employer-provided health insurance. 
Table 6 therefore divides the sample into those with and those without employer-provided health insurance on their current jobs. ${ }^{24}$ For those with health insurance (column 1), the effect of continuation coverage is even greater than that estimated for the full sample and is more significant as well. The coefficient estimate implies that one year of continuation coverage leads to an increase in the likelihood of changing jobs of .84 percentage points; this is $14 \%$ of the baseline mobility rate for this group.

The second column of Table 6 looks at those without health insurance. In fact, there is a positive effect of the mandates on mobility for this group as well. This suggests that the passage of the 'continuation regulations was correlated with other factors causing increases in mobility in these state/years. However, the implied mobility increase for those without health insurance is not significant, and it represents only $3.4 \%$ of the baseline mobility rate for this group. Furthermore, if we use the estimated effect of these mandates on mobility for those without health insurance to control for secular changes in mobility, the evidence in Table 6 is consistent with that in Table 5, namely that continuation mandates increase mobility by about 10 percent (that is, $14 \%$ minus $3.4 \%$ ).

As noted earlier, the effect of continuation mandates will be mitigated by factors such as the extent to which firms self-insure (as they are exempt from state mandates) and the distribution of workers by firm size (as small firms are exempt from the federal mandates). In order to appropriately measure the effect of continuation coverage, we need to account for variation in these factors across states. We do this by constructing a "corrected" months of coverage variable. The Appendix details the calculation of these correction factors, one for those who have employer-

\footnotetext{
24 Note that this is an imperfect split due to the noise in assigning insurance coverage to a given joh for persons who change jobs in consecutive quarters.
} 
provided health insurance which adjusts for the factors just described, and one for all individuals which also adjusts for the likelihood of being insured.

Briefly, we use unpublished data from the Health Insurance Association and America (HIAA) and the Current Population Survey to estimate, by state, the fraction of workers actually offered employer-provided health insurance, the fraction in self-insured firms, and the fraction in small ( $<20$ employee) firms. If a state law only is in effect, we adjust the months of coverage to reflect the fact that the state law applies only to those offered insurance and only to those who do not work in a firm that self-insures. If a federal law only is in effect, we adjust the months of coverage by the fraction of individuals who are offered insurance and the fraction who work in small firms. When both a state and federal law are in effect, the corrected months of coverage accounts for the fact that the state law will affect insured individuals working in small firms that do not self-insure. When we adjust for these factors, the average length of continuation coverage in states that offer coverage falls from 6.88 months to 4.55 months.

The results using the corrected months of coverage variables are presented in Table 7 . The findings are very similar; the magnitudes of the coefficients are somewhat increased, as are the standard errors, although the effects are still highly significant. This is to be expected from a procedure which multiplies our coefficient of interest by a noisy correction factor which is less than one. The estimates in columns 1 and 2 of Table 7 suggest that one year of coverage increases mobility by between $12 \%$ and $15 \% .^{25}$

Finally, one potential problem with this model which was discussed above is that the variable of interest is measured with considerable noise. In particular, we are not focusing on the individuals

\footnotetext{
2 This regression is not run for those without health insurance, since their corrected months of continuation coverage is zero by definition.
} 
who most value their health insurance benefits and for whom the limited portability of continuation mandates may be the most useful. One such group for whom these mandates should be important is married workers, whose higher family medical expenditures may increase their valuation of health insurance. It is true that married workers are more likely to have coverage from an alternative source (namely their spouse), and thus potentially less likely to need continuation benefits. Madrian (1992) estimates that 33\% of married men had coverage through a spouse's employment in 1987. But family heaith care expenditures for married men are three times greater than those for single men. ${ }^{20}$ Thus, on net, being married would appear to raise the costs of leaving a job with health insurance. ${ }^{27}$

In results not reported, we have repeated the regressions of Table 5-7 for only married individuals and found slightly larger, although less precisely estimated, effects. For the basic specification, there is a .0085 percentage point increase in mobility which is $9.7 \%$ of the baseline mobility rate for this subsample. This implies that the mandates had a slightly larger effect on a population which was more likely to be affected by their presence.

\section{Continuation Mandates and Insurance Coverage}

A necessary (but not sufficient) precondition for continuation of coverage mandates to affect job mobility is that they affect insurance coverage. ${ }^{28}$ Moreover, the effects of these mandates on

26 Authors' tabulations from the 1980 National Medical Care Utilization and Expenditure Survey.

${ }^{27}$ Of course, if these higher expected expenditures are reflected in lower wages, then the mobility distortion for married males will be no higher than that for single males. Whether shifting by marital status is feasible is uncertain; see Gruber (1992b). for evidence in favor of the ability of employers to shift increased insurance costs to the wages of identifiable demographic groups within the workplace.

Some evidence that these mandates did increase coverage among those who left their jobs and remained unemployed is presented in Klerman and Rahman (1992). However, for comparability to our mobility regressions, we wish to examine the effects on the insurance coverage of any worker who leaves his job. 
insurance coverage may be important for assessing their welfare implications. Ostensibly, the purpose of these mandates was to correct a failure in the market for private insurance for job leavers. Such market failure seems likely given the adverse selection in the takeup of continuation coverage benefits documented by Huth (1991) and Long and Marquis (1992). In this case, increasing insurance coverage among those who would have left their jobs even in the absence of the regulations represents a clear welfare improvement. However, the welfare implications of reducing job lock are less clear, as discussed earlier. Thus, the net welfare effects of the mandates may depend on the relation between their effect on "inframarginal" individuals, who would have left their jobs in the absence of a mandate, and their effects on "marginal" individuals whose mobility decision is made in response to the mandate.

To model the effect of these mandates on insurance coverage, we examine the sample of worker/quarters in which there was a job change. We then create a dummy variable which is equal to one if an individual has insurance coverage in the quarter after his job change. We regress this dummy variable on the set of covariates used earlier. ${ }^{29}$ These results are presented in Table 8 . Since there are relatively few individuals in some states, we run the regressions without state effects; the coefficients are quite similar, although less precisely estimated, if state effects are included. Once again, we use a probit specification.

For the full sample (column 1), the coefficient on months of coverage suggests that continuation mandates have a positive but insignificant effect on the probability of being insured after changing jobs. The implied increase in insurance coverage is 1.4 percentage points. In the second and third columns of Table 8 , we split the sample as before into those with and without health

\footnotetext{
${ }^{20}$ We do not include the job characteristics (hourly wage, industry, and occupation), since it isn' $\mathrm{t}$ obvious which job (the one left or the one gained) to use. The resulis are similar if the characteristics of the former job are included.
} 
insurance. For those with health insurance, the effect of continuation coverage is statistically significant and implies a 4.1 percentage point increase in insurance coverage after changing jobs. For those without employer-provided health insurance, the likelihood of having insurance after leaving a job falls by 2.2 percentage points. Thus, the effect for those with health insurance is strengthened if we consider other trends correlated with the passage of the mandates. Compared to the effect on mobility for those with health insurance ( 0.84 percentage points), this result suggests that the effect of the mandates was largely to cover individuals who would have left their jobs even in the absence of continuation availability.

\section{Conclusion}

The problem of job-lock has caught the public's anention and one key measure of the success of health care reform in the U.S. will be its ability to reduce insurance-induced mobility reductions. However, reducing this distortion is only one of a number of goals towards which reform must strive, goals which may be not be mutually compatible. Thus, if it is possible to alleviate much of the job-lock problem by modest policy changes, this may offer policy-makers more degrees of freedom with which to design other elements of the reform package.

This research suggests that continuation benefits may have had some success in alleviating job-lock. We find that one year of continuation benefits is associated with a $5 \%$ increase in mobility for those with health insurance. This is moderately large in reference to the estimates of job-lock provided by Madrian (1992). Furthermore, continuation mandates were successful in increasing the insurance coverage of job leavers above and beyond inducing job leaving behavior.

Our findings imply that a substantial portion of the job-lock problem can be alleviated by limited portability. This is supportive of Holtz-Eakin's (1993) contention that job-lock is a short-run 
problem. Presumably the expansion of eligibility for COBRA coverage after 1990 that allows for coverage even after individuals are employed if they are subject to length of service requirements or preexisting conditions exclusions will only strengthen its effects. Future work to model the effects of this change would be very useful.

While our estimates imply that limited portability does remove a sizeable share of job-lock. there are a number of dimensions along which this portability may have to be enhanced to mitigate this distortion for the entire population. The important point from an economic perspective is that the policy-changes required to fully remove job-lock may be very costly relative to the changes necessary to greatly mitigate its effects. If even this limited portability had a substantial effect, policies which strengthen COBRA, while perhaps allowing for a public reinsurance pool for the worst risks, may be all that is necessary to greatly reduce this key labor market distortion. 


\section{BIBLIOGRAPHY}

Bartel, Ann and George Borjas (1977). "Middle-Age Job Mobility: Its Determinants and Consequences." In Seymour Wolfbein, editor, Men in the Pre-Retirement Years. Philadelphia: Temple University Press.

Congressional Research Service (1988). Costs and Effects of Extending Health Insurance Coverage. Washington, DC: Library of Congress.

Cotton, Paul (1991). "Preexisting Conditions 'Hold Americans Hostage' to Employers and Insurance." Journal of the American Medical Association, vol. 265, 2451-2453.

Diamond, Peter A. and Jerry A. Hausman (1984). "The Retirement and Unemployment Behavior of Older Men." In Henry J. Aaron and Gary Burtless, editors, Retirement and Economic Behavior. Washington, DC: Brookings Institution.

Diamond, Peter A. (1992). "A Proposal for Universal Coverage Through Compulsory Group Health Insurance." Massachusetts Institute of Technology, Department of Economics, mimeo. Cambridge, MA.

Flynn, Patrice (1992). "Employment-Based Health Insurance: Coverage Under COBRA Continuation Rules." In U.S. Department of Labor, Pension and Welfare Benefits Administration, Health Benefits and the Workforce. Washington, DC: Government Printing Office.

Gruber, Jonathan (1992a). "State Mandated Benefits and Employer-Provided Health Insurance," forthcoming Journal of Public Economics.

Gruber, Jonathan (1992b). "The Efficiency of a Group-Specific Mandated Benefit: Evidence From Health Insurance Benefits for Maternity," forthcoming American Economic Review.

Gruber, Jonathan and Brigitte C. Madrian (1993). "Health Insurance and Early Retirement: Evidence From the Availability of Continuation Coverage." Massachusetts Institute of Technology, Department of Economics, mimeo.

Hewitt Associates (1985). Continuation of Group Medical Coverage-A Study of State Laws. Lincolnshire, IL: Hewitt Associates.

Holtz-Eakin, Douglas (1993). "Health Insurance Provision and Labor Market Efficiency in the United States and Germany." Syracuse University, Department of Economics, mimeo. Syracuse, NY. 
Klerman, Jacob Alex and Omar Rahman (1992). "Employment Change and Continuation of Health Insurance Coverage." In U.S. Department of Labor, Pension and Welfare Benefits Administration, Health Benefits and the Workforce. Washington, DC: Government Printing Office.

Madrian, Brigitte C. (1992). "Employment-Based Health Insurance and Job Mobility: Is There Evidence of Job-Lock?". Massachusetts Instirute of Technology, Department of Economics, mimeo. Cambridge, MA.

Mincer, Jacob (1986). "Wage Changes in Job Changes." In R.G. Ehrenberg, editor, Research in Labor Economics, vol. 8, part A. Greenwich, CT: JAI Press.

Minter, Caroline (1992). "Tests of Job-Matching Models Using Turnover and Wage Growth." Massachusetts Institute of Technology mimeo. Cambridge, MA.

Mitchell, Olivia S. (1982). "Fringe Benefits and Labor Mobility." Journal of Human Resources, vol. $17,286-298$.

Rosen, Sherwin (1986). "The Theory of Equalizing Differences." In Orley Ashenfelter and Richard Layard, editors, Handbook of Labor Economics, Volume I. Amsterdam: North-Holland.

Thompson Publishing Group, Inc. (1992). Employer's Handbook: Mandated Health Benefits--The COBRA Guide. Salisbury, MD: Thompson Publishing Group.

Topel, Robert (1986). "Job Mobility, Search and Earnings Growth: A Reinterpretation of Human Capital Earnings Functions." In R.G. Ehrenberg, editor, Research in Labor Economics, vol. 8, part A. Greenwich, CT: JAI Press.

U.S. Department of Labor, Bureau of Labor Statistics (1989). Employee Benefits in Medium and Large Firms. Washington DC: Government Printing Office. 


\section{APPENDIX \\ Calculating Correction Factors for the Impact of State and Federal Continuation Laws}

In our basic regression specification, we assign to individuals the maximum number of months of continuation coverage mandated under either federal or state law. There are several factors, however, that lead to less than full coverage of these laws. First, those who are not covered by employer-provided health insurance should not be affected by any of these laws. Before the federal law took effect, employees of self-insured firms should not have been affected by the state laws because, under the 1974 Employee Retirement Income and Security Act (ERISA), self-insured firms are exempt from state mandates. And those who work in firms with fewer than 20 employees will not be affected by the federal law, which does not apply to small firms, although they will be influenced by state laws which pertain to all firms.

To the extent that these factors differ across states, we would expect laws which mandate equivalent months of coverage to have different effects. To account for the less than full coverage of these laws, we compute a "corrected" measure of months of coverage. As before, if there is no state or federal law in effect, we assign no months of coverage to an individual. If a state law is operative but the federal law has not yet taken effect, the corrected months of coverage equals

$$
\left[\begin{array}{c}
\text { Months } \\
\text { of State } \\
\text { Coverage }
\end{array}\right] \cdot\left[\left(\begin{array}{c}
\text { Fraction } \\
\text { Offered } \\
\text { Insurance }
\end{array}\right] \cdot\left(1-\begin{array}{c}
\text { Fraction in } \\
\text { Self-Insured Firm }
\end{array}\right)\right]
$$

If the federal law is in effect but there is no state law, the corrected months of coverage equals 


$$
\left[\begin{array}{c}
\text { Months } \\
\text { of Federal } \\
\text { Coverage }
\end{array}\right] \cdot\left[\left(\begin{array}{c}
\text { Fraction } \\
\text { Offered } \\
\text { Insurance }
\end{array}\right] \cdot\left[\begin{array}{c}
\text { Fraction } \\
- \text { Insured in } \\
<20 \text { Firm }
\end{array}\right)\right] \text {. }
$$

Finally, if both a state and the federal law are in place, the corrected months of coverage equals

$$
\begin{aligned}
& {\left[\begin{array}{c}
\text { Momhs } \\
\text { of Federal } \\
\text { Coverage }
\end{array}\right) \cdot\left[\left(\begin{array}{c}
\text { Fraction } \\
\text { offered } \\
\text { Insurance }
\end{array}\right) \cdot\left(1-\begin{array}{c}
\text { Fraction } \\
\text { Insured in } \\
<20 \text { Firm }
\end{array}\right)\right]+} \\
& {\left[\begin{array}{c}
\text { Months } \\
\text { of Stale } \\
\text { Covernge }
\end{array}\right] \cdot\left[\left(\begin{array}{c}
\text { Fraction } \\
\text { offered } \\
\text { Insurance }
\end{array}\right) \cdot\left(1-\begin{array}{c}
\text { Fraction in } \\
\text { Self-Insured Firm }
\end{array}\right) \cdot\left(\begin{array}{c}
\text { Fraction } \\
\text { Insured in } \\
<20 \text { Firm }
\end{array}\right]\right]}
\end{aligned}
$$

We measure the various components of the corrected months of coverage using data from the Health Insurance Association of America (HIAA) 1989 employer survey and the May 1988 Current Population Survey (CPS) pension supplement. In using data from this late date, we are assuming that these factors are constant over time. This is clearly not true for self-insurance which grew dramatically during the 1980 s. As long as self-insurance did not grow in a way correlated with the passage of these laws, however, this will not bias our results. Recent research suggests that mandates play little role in the firm's decision to self-insure.

The fraction of workers offered employer-provided health insurance and the fraction of insured workers in firms with less than 20 employees are measured directly, by state, from the CPS. The fraction in self-insured firms are estimated from the HIAA data. In using the HIAA data, we have tried two different approaches. The first is to caiculate the average of these quantities by state. This strategy, however, is problematic, as the state cell sizes in the HIAA data are quite small. Our second approach, therefore, is to use the HIAA data to run a regression predicting the rate of selfinsurance as a function of firm size, industry, and census division. We then use these estimated coefficients to impute values of these quantities for each individual in the May CPS. Our correction factors are state-wide averages of these imputed values. 
We did this imputation for all male workers between 20 and 54 years old. In our empirical work, we use the corrected months of coverage computed as outlined above when the sample includes all workers. When the sample is restricted to only those with health insurance, we use a similarly constructed corrected months of coverage which does not adjust for the fraction of workers in the state with employer-provided health insurance. 


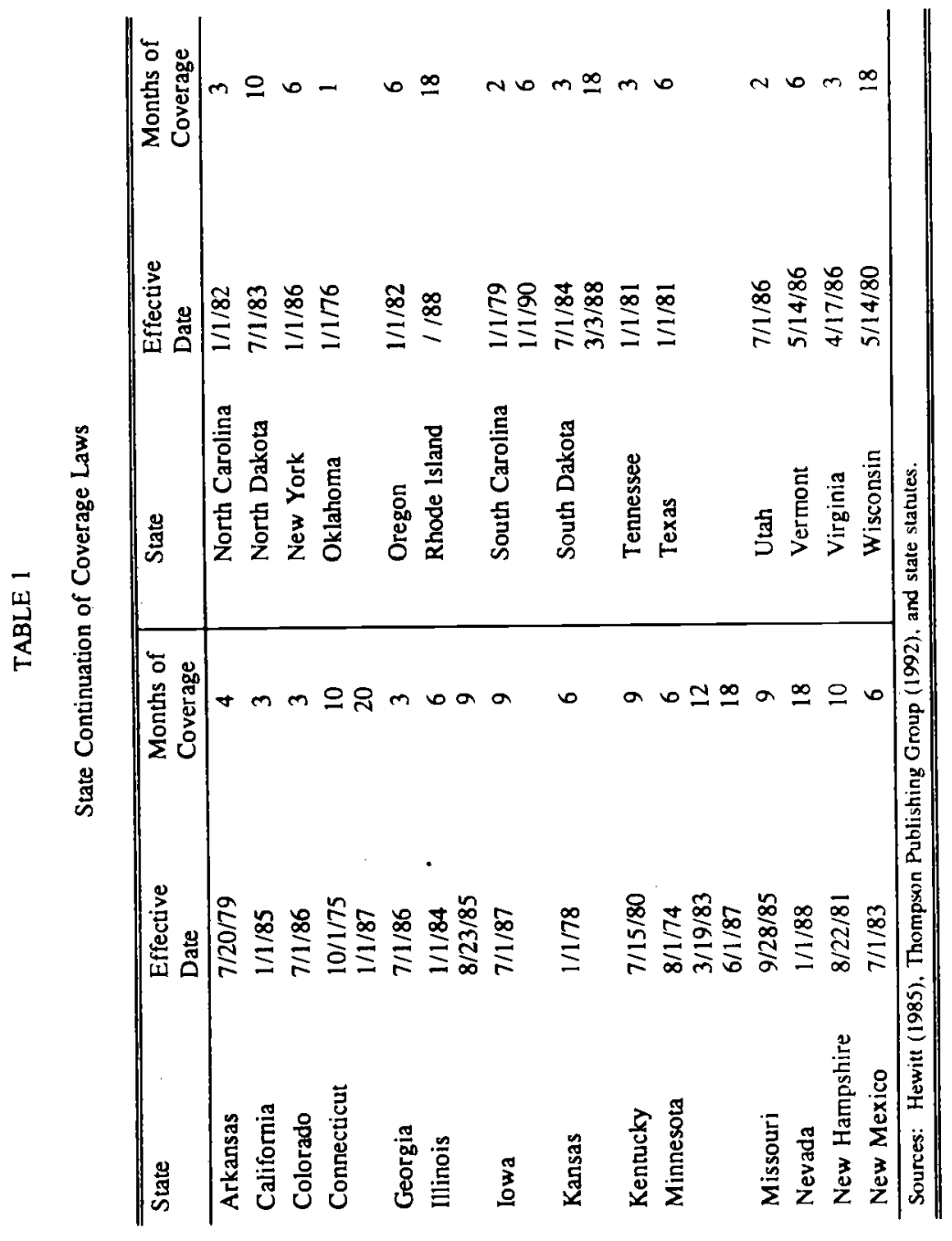


TABLE 2

Group and Nongroup Health Insurance Benefits

\begin{tabular}{l|cc}
\hline \hline & \multicolumn{1}{|c}{$\begin{array}{c}\text { Fraction of Individuals with } \\
\text { Specified Benefit }\end{array}$} \\
\cline { 2 - 2 } & Group Plans & Nongroup Plans \\
\hline A. Primary benefits & & $39.1 \%$ \\
Major medical coverage & $86.9 \%$ & 91.4 \\
Hospital room and board & 98.4 & 91.6 \\
Surgery & 97.6 & 40.4 \\
Physician office visit & 87.9 & \\
B. Other benefits & & 54.0 \\
Ambulance & 89.0 & 66.0 \\
Outpatient diagnostic services & 95.9 & 30.3 \\
Prescribed medicines & 87.3 & 66.0 \\
Mental health & 92.2 & \\
& & 61.3 \\
\hline C. Generosity of benefits & & 38.2 \\
(conditional on having benefit) & & 60.0 \\
Major medical deductible < \$100 & 94.3 & \\
Full semi-private room charge & 77.8 & \\
80-100\% of UCR surgical charge & 70.6 & \\
80-100\% of UCR physician charge & 91.8 & \\
\hline Source: Farley (1986), Tables 45-58. & & \\
\hline \hline
\end{tabular}


TABLE 3

Sources of Health Insurance Coverage

\begin{tabular}{l|ccc}
\hline \hline & All & Job Stayers & Job Leavers \\
\hline Employer-provided & & & \\
Any & $66.1 \%$ & $72.0 \%$ & $45.1 \%$ \\
Own name & 57.5 & 64.2 & 33.9 \\
Union & 3.5 & 3.6 & 3.1 \\
Other group policy & 1.2 & 1.0 & 1.9 \\
Non-group policy & 6.1 & 6.2 & 5.6 \\
CHAMPUS & 2.5 & 2.1 & 4.0 \\
Medicaid & 1.1 & 0.6 & 2.9 \\
\hline
\end{tabular}

Authors' calculation using data from the 1987 National Medical Expenditure Survey. 
TABLE 4

Descriptive Statistics

\begin{tabular}{l|c|c}
\hline \hline Variable & Mean & $\begin{array}{c}\text { Standard } \\
\text { Deviation }\end{array}$ \\
\hline Non-white & 0.113 & 0.316 \\
Years of school completed & 12.94 & 3.021 \\
Experience & 16.42 & 10.044 \\
Log hourly wage & $\$ 2.20$ & 0.619 \\
Holds employer-provided & 0.772 & 0.420 \\
health insurance & 0.101 & 0.301 \\
Leave Job & 6.88 & 7.257 \\
Months of continuation & & \\
coverage & &
\end{tabular}

Authors' calculation using data on men aged 20-54 from the 1984-1987 Panels of the Survey of Income and Program Participation. The sample consists of 155,151 quarterly observations on 29,841 individuals. 
TABLE 5

Effect of Continuation Coverage on Job Turnover

\begin{tabular}{l|c|c|c}
\hline \hline & $(1)$ & $(2)$ & $(3)$ \\
\hline A. Coefficient Estimates & & & \\
Non-white & .0118 & -.0087 & -.0087 \\
Education & $(.0142)$ & $(.0144)$ & $(.0144)$ \\
& -.0130 & -.0072 & -.0071 \\
Experience & $(.0019)$ & $(.0020)$ & $(.0020)$ \\
& -.0127 & -.0106 & -.0106 \\
Log hourly wage & $(.0005)$ & $(.0005)$ & $(.0005)$ \\
& -.2645 & -.1327 & -.1338 \\
Health insurance & $(.0078)$ & $(.0084)$ & $(.0084)$ \\
& -- & -.5546 & -.5542 \\
Months of coverage & - & $(.0108)$ & $(.0108)$ \\
& & - & .0046 \\
Log-likelihood & $-47,098$ & $-45,794$ & $(.0011)$ \\
$\mathrm{N}=$ Sample Size & $\mathrm{N}=155,151$ & $\mathrm{~N}=155,151$ & $\mathrm{~N}=155,785$ \\
B. Marginal effect of 12 months & -- &.- & .0087 \\
of continuation coverage \\
[\% of baseline mobility rate]
\end{tabular}

The table gives estimates from a probit equation for whether or not an individual changed jobs in a quarter using data from the 1984-1987 Survey of Income and Program Participation. The sample is comprised of men aged 20-54. Coefficients for panel, state, month, industry and occupation dummies are not reported. 
TABLE 6

Effect of Continuation Coverage on Job Turnover

\begin{tabular}{l|c|c}
\hline \hline & $\begin{array}{c}\text { Have Health } \\
\text { Insurance }\end{array}$ & $\begin{array}{c}\text { No Health } \\
\text { Insurance }\end{array}$ \\
\hline A. Coefficient Estimates & .0038 & -.0238 \\
Non-white & $(.0195)$ & $(.0216)$ \\
Education & -.0105 & -.0026 \\
Experience & $(.0026)$ & $(.0030)$ \\
& -.0103 & -.0103 \\
Log hourly wage & $(.0007)$ & $(.0008)$ \\
& -.1770 & -.0862 \\
Months of coverage & $(.0118)$ & $(.0121)$ \\
$\quad \begin{array}{l}\text { Log-likelihood } \\
\text { N=Sample Size }\end{array}$ & $(.0059$ & .0021 \\
B. Marginal effect of 12 months & $\mathbf{2 7 , 1 8 0}$ & $(.0018)$ \\
of continuation coverage & {$[14.3 \%]$} & $-18,469$ \\
[\% of baseline mobility rate] & .0084 & $\mathrm{~N}=35,451$ \\
\end{tabular}

The table gives estimates from a probit equation for whether or not an individual changed jobs in a quarter using datu from the 1984-1987 Survey of Income and Program Participation. The sample is comprised of men aged 20-54.

Coefficients for panel, state, month, industry and occupation dummies are not reported. 
TABLE 7

Effect of Continuation Coverage on Job Turnover (Corrected)

\begin{tabular}{|c|c|c|}
\hline & Full Sample & $\begin{array}{l}\text { Have Health } \\
\text { Insurance }\end{array}$ \\
\hline \multicolumn{3}{|l|}{ A. Coefficient Estimates } \\
\hline Non-white & $\begin{array}{l}-.0088 \\
(.0144)\end{array}$ & $\begin{array}{c}.0038 \\
(.0195)\end{array}$ \\
\hline Education & $\begin{array}{l}-.0072 \\
(.0020)\end{array}$ & $\begin{array}{l}-.0105 \\
(.0026)\end{array}$ \\
\hline Experience & $\begin{array}{l}-.0106 \\
(.0005)\end{array}$ & $\begin{array}{l}-.0103 \\
(.0007)\end{array}$ \\
\hline Log hourly wage & $\begin{array}{l}-.1339 \\
(.0084)\end{array}$ & $\begin{array}{l}-.1769 \\
(.0118)\end{array}$ \\
\hline Health insurance & $\begin{array}{l}-.5542 \\
(.0108)\end{array}$ & -- \\
\hline Months of coverage & $\begin{array}{c}.0063 \\
(.0016)\end{array}$ & $\begin{array}{l}.0063 \\
(.0017)\end{array}$ \\
\hline $\begin{array}{l}\text { Log-likelihood } \\
\mathrm{N}=\text { Sample Size }\end{array}$ & $\begin{array}{c}-45,785 \\
N=155,151\end{array}$ & $\begin{array}{c}-27,181 \\
N=119,700\end{array}$ \\
\hline $\begin{array}{l}\text { B. Margiral effect of } 12 \text { months } \\
\text { of continuation coverage } \\
\text { [\% of baseline mobility rate] }\end{array}$ & $\begin{array}{c}.0122 \\
{[12.7 \%]}\end{array}$ & $\begin{array}{r}.0091 \\
|15.3 \%|\end{array}$ \\
\hline
\end{tabular}

The table gives estimates from a probit equation for whether or not an individual changed jobs in a quarter using data from the 1984-1987 Survey of Income and Program Participation. The sample is comprised of men aged 20-54.

Coefficients for panel, stale, month, industry and occupation dummies are not reported. 


\section{TABLE 8}

The Effect of Continuation Mandates on Insurance Coverage

\begin{tabular}{l|c|c|c}
\hline \hline & Full Sample & $\begin{array}{c}\text { Have Health } \\
\text { Insurance }\end{array}$ & $\begin{array}{c}\text { No Health } \\
\text { Insurance }\end{array}$ \\
\hline A. Coefficient Estimates & & & \\
Non-white & -.2961 & -.3227 & -.1392 \\
Education & $(.0350)$ & $(.0617)$ & $(.0500)$ \\
& .1242 & .0929 & .1179 \\
Age & $(.0046)$ & $(.0077)$ & $(.0070)$ \\
& .0112 & .0368 & -.0289 \\
Age & $(.0096)$ & $(.0174)$ & $(.0146)$ \\
& .0001 & -.0002 & .0005 \\
Months of Coverage & $(.0001)$ & $(.0002)$ & $(.0002)$ \\
& .0034 & .0112 & -.0048 \\
Log-likelihood & $(.0027)$ & $(.0048)$ & $(.0043)$ \\
$N=$ Sample Size & $-7,535$ & $-2,513$ & $-3,347$ \\
B. Marginal effect of 12 months & .0145 & .0411 & -.0219 \\
of continuation coverage & & & \\
\hline
\end{tabular}

The table gives estimates of the probability of being insured in the quarter after a job change using data from the 1984-1987 Survey of Income and Program Participation. The sample is comprised on men aged 20-54 who change jobs of become unemployed.

Coefficients for panel dummies are not reported. 